\title{
Plântulas de soja 'Tracajá' expostas ao ozônio sob condições controladas
}

\author{
Patricia Bulbovas(1), Silvia Ribeiro de Souza ${ }^{(1)}$, Regina Maria de Moraes ${ }^{(1)}$, Flávio Luizão(2) e Paulo Artaxo ${ }^{(3)}$
}

(1)Instituto de Botânica, Seção de Ecologia, Caixa Postal 3005, CEP 01061-970 São Paulo, SP. E-mail: patibul@usp.br, souzasrd@terra.com.br, regmorae@yahoo.com.br (2)Instituto Nacional de Pesquisas da Amazônia, Caixa Postal 478, CEP 69011-970 Manaus, AM. E-mail: fluizao@inpa.gov.br (3)Universidade de São Paulo, Instituto de Física, Rua do Matão, Travessa R, o 187, CEP 05508-900 São Paulo, SP. E-mail: artaxo@if.usp.br

Resumo - O objetivo deste trabalho foi avaliar o crescimento inicial, acúmulo de biomassa, trocas gasosas e defesas antioxidativas de soja 'Tracajá', cultivada na Região Amazônica, exposta ao ozônio sob condições controladas. Sementes germinadas em vasos foram levadas para duas câmaras, uma com ar filtrado (AF) e outra com ar filtrado mais $30 \mathrm{ppb}$ de ozônio $\left(\mathrm{AF}+\mathrm{O}_{3}\right)$. Aos 10 e 20 dias após a semeadura, as trocas gasosas, crescimento em altura e acúmulo de biomassa foram medidos; aos 20 dias após a semeadura, as defesas antioxidativas (ácido ascórbico e superóxido dismutase) foram analisadas. Aos 10 dias após a semeadura, a fotossíntese líquida, condutância estomática, transpiração, altura, área foliar e biomassa foram 16, 27, 11, 22, 29 e 18\% menores, respectivamente, no tratamento $\mathrm{AF}+\mathrm{O}_{3}$. Aos 20 dias após a semeadura, além dessas variáveis, comprimento da raiz, diâmetro do caule e razão raiz:parte aérea foram 10,15 e 12\% menores, respectivamente, apesar da concentração de ácido ascórbico e da atividade da superóxido dismutase terem aumentado. Plântulas de soja 'Tracajá' apresentam baixa tolerância à concentração de 30 ppb de ozônio.

Termos para indexação: Glycine max, poluição atmosférica, antioxidantes, trocas gasosas, crescimento.

\section{Soybean 'Tracajá' seedlings exposed to ozone under controlled conditions}

\begin{abstract}
The objective of this work was to assess initial growth, biomass production, gas exchange and antioxidative defenses of soybean 'Tracajá' seedlings, cultivated in the Amazonian region, exposed to ozone under controlled conditions. Seeds germinated in pots were placed in two chambers, one with filtered air (AF) and other with filtered air plus $30 \mathrm{ppb}$ of ozone $\left(\mathrm{AF}+\mathrm{O}_{3}\right)$. At 10 and 20 days after sowing, gas exchange, growth and biomass were measured; at 20 days after sowing, antioxidative defenses (ascorbic acid and superoxide dismutase) were analyzed. Net photosynthesis, stomatal conductance, transpiration rate, height, leaf area and biomass were $16,27,11,22,29$ and $18 \%$ smaller, respectively, in $\mathrm{AF}+\mathrm{O}_{3}$ at 10 days after sowing. At 20 days after sowing, besides this parameters, root length, stem diameter and root:shoot ratio were 10,15 and $12 \%$ smaller, respectively, although ascorbic acid concentrations and superoxide dismutase activity increased. Soybean 'Tracajá' seedlings have low tolerance to concentration of $30 \mathrm{ppb}$ of ozone.
\end{abstract}

Index terms: Glycine max, air pollution, antioxidants, gas exchange, growth.

\section{Introdução}

A soja (Glycine max) é uma das principais oleaginosas produzidas no mundo e uma importante matéria-prima empregada na elaboração de diversos produtos, desde óleo até papel. Em virtude de seu valor econômico e de sua potencialidade de cultivo em diversas condições, a cultura dessa leguminosa tem sido objeto de constante investimento em tecnologias na agricultura. Isto vem permitindo, entre outras coisas, o aumento significativo de sua produtividade e a expansão de fronteiras agrícolas. Atualmente, a soja é a cultura de grãos mais importante do Brasil, e é cultivada em diferentes regiões do país (Mello Filho et al., 2004), até mesmo na região sul da Amazônia.

A alteração no uso do solo amazônico em virtude do avanço da agricultura e pecuária tem sido responsável por emissões significativas de gases e partículas para a atmosfera, uma vez que a queimada é comumente usada na região para a limpeza de áreas de plantio após a retirada da floresta (Artaxo et al., 1998, 2003, 2005).

Entre os gases emitidos estão os precursores do ozônio $\left(\mathrm{O}_{3}\right)$, o qual é formado na atmosfera por meio de reações fotoquímicas. A emissão destes gases faz com que as 
concentrações de $\mathrm{O}_{3}$ atinjam níveis que podem ser prejudiciais à floresta e às culturas agrícolas da região, mesmo a milhares de quilômetros das áreas queimadas (Cordova Leal, 2003; Artaxo et al., 2005; Freitas et al., 2005; Guyon et al., 2005).

Na Região Amazônica, a concentração média anual de ozônio estava entre 30-40 ppb na década de 1990, porém, por meio de modelagem das tendências futuras de emissões de óxidos de nitrogênio, um dos gases precursores do ozônio, está previsto que esta concentração alcance o valor médio anual de $60 \mathrm{ppb}$ até 2030 (Emberson, 2003). Ambos os níveis configuram uma exposição crônica, ou seja, concentrações não muito altas de ozônio por longo período, mas que podem causar desequilíbrios bioquímicos e fisiológicos, como efeitos sobre sistemas enzimáticos e alterações nas trocas gasosas, respectivamente, que interferem no crescimento, causando perda de biomassa e produção de grãos (Morgan et al., 2003; Ashmore, 2005; Filella et al., 2005). O valor de 60 ppb é considerado fitotóxico e capaz de provocar redução da produtividade de espécies sensíveis (Fuhrer et al., 1997). Estudos indicam que a soja é uma cultura sensível ao ozônio; dependendo do nível de tolerância da cultivar, pode ocorrer até $80 \%$ de redução da área foliar e 50\% de perda da produção de sementes (Morgan et al., 2003; Ashmore, 2005).

Há a necessidade de se estudar mais as espécies cultivadas e suas diferentes variedades, para conhecer as mais tolerantes aos efeitos negativos do ozônio (Fuhrer \& Booker, 2003). Apesar da previsão de aumento dos níveis de ozônio no Brasil, principalmente devido às queimadas na Amazônia, ainda é desconhecido seu efeito sobre as espécies agrícolas aqui cultivadas e suas cultivares, que são diferentes das encontradas nos Estados Unidos e países da Europa, onde este tipo de estudo vem sendo realizado nas últimas décadas. Na Amazônia, em particular, não se conhece a resistência das variedades que têm sido cultivadas, principalmente no Sul da região, progressivamente cultivada com soja e mais exposta aos efeitos de poluentes atmosféricos das queimadas.

O objetivo deste trabalho foi avaliar o crescimento inicial, acúmulo de biomassa, trocas gasosas e defesas antioxidativas de plântulas de soja 'Tracajá', cultivada na RegiãoAmazônica, exposta ao ozônio sob condições controladas.

\section{Material e Métodos}

A exposição de plântulas de soja ao ozônio foi realizada em laboratório, na Seção de Ecologia, do
Instituto de Botânica, São Paulo, SP, em sistemas de câmaras fechadas. Estas câmaras consistem de filmes de Teflon fixados em armação de aço inoxidável. Em sua parte inferior há um suporte para vasos e, abaixo, um reservatório com água, ambos de aço inoxidável. Nessas câmaras, as plântulas foram expostas a dois tratamentos: ar filtrado (AF) isento de poluentes, e ar filtrado enriquecido com $30 \pm 14$ ppb de ozônio $\left(\mathrm{AF}+\mathrm{O}_{3}\right)$ por 6 horas diárias.

$\mathrm{O}$ ar introduzido nas câmaras foi captado do ambiente por um compressor e conduzido para um sistema de filtragem contendo filtro secador, com sílica, e filtros para eliminar contaminantes atmosféricos, com carvão ativado e permanganato de potássio. Depois de filtrado, uma parte do ar foi conduzida para uma das câmaras (AF) e outra para um compartimento que continha dois tubos cilíndricos, denominados misturadores. Nesses tubos ocorreu a mistura do ar filtrado com o ozônio gerado por um ozonizador, que foi, então, levado para a outra câmara $\left(\mathrm{AF}+\mathrm{O}_{3}\right)$. A concentração de ozônio nas câmaras foi medida por meio de um analisador de ozônio modelo EC 9810B da marca Ecotech.

Sementes de soja 'Tracajá', fornecidas pela Embrapa Soja, Londrina, PR, foram colocadas para germinar, em janeiro de 2006, em seis vasos de aço inoxidável, com capacidade de $1 \mathrm{~m}^{3}$. Os vasos foram preenchidos com uma camada de vermiculita, uma de substrato comercial Plantmax (Eucatex - Brasil) e embebidos com água. Sobre o substrato foram postas 16 sementes, que foram cobertas com uma fina camada de vermiculita. Três vasos foram colocados em cada câmara. As plântulas germinadas foram irrigadas por capilaridade, através de barbantes de náilon inseridos na base dos vasos, sendo que uma de suas extremidades ficou em contato com as raízes e a outra metade mergulhada no reservatório de água.

Aos 10 dias após a semeadura, foram realizadas medidas de trocas gasosas em 9 plântulas de cada câmara, por meio de um analisador de gases por infravermelho (LI-6400, LI-COR, NE, USA). As taxas de fotossíntese líquida, condutância estomática e transpiração foram medidas entre 9e 11h da manhã, sob condições ambientais, com densidade média de fluxo de fótons fotossinteticamente ativos de $1.400 \mu \mathrm{mol} \mathrm{m}{ }^{-2} \mathrm{~s}^{-1}$, temperatura média de $28^{\circ} \mathrm{C}$ e umidade relativa do ar média de $73 \%$. Foram retiradas 10 plântulas de cada tratamento para avaliar o crescimento e acúmulo de biomassa - altura, diâmetro, comprimento da raiz, área foliar, biomassa total e razão entre biomassa radicular e epígea. As plântulas restantes permaneceram nas câmaras de fumigação. Aos 20 dias após a semeadura, foram 
novamente realizadas medidas de trocas gasosas, crescimento e acúmulo de biomassa. Também foram analisadas as defesas antioxidativas (ácido ascórbico e enzima superóxido dismutase). Todo este procedimento experimental foi realizado em duplicata.

A fim de avaliar a concentração de ácido ascórbico (AA), folhas frescas $(0,5 \mathrm{~g})$ foram homogeneizadas com $12 \mathrm{~mL}$ de solução aquosa de etileno diamina ácido tetracético - sal de sódio (EDTA-Na $)(0,07 \%)$ e ácido oxálico $(0,5 \%)$. O extrato resultante foi centrifugado $\left(40.000 \mathrm{~g}, 30 \mathrm{~min}, \mathrm{a} 2^{\circ} \mathrm{C}\right)$. Leituras foram realizadas em espectrofotômetro $(\lambda=520 \mathrm{~nm})$, após o acréscimo de 2,5 mL de solução 2,6 diclorofenol-indofenol sal de sódio dihidratado (DCPiP) $(0,02 \%)$ (primeira leitura) e $0,05 \mathrm{~mL}$ de ácido ascórbico $1 \%$ ao sobrenadante (segunda leitura). O conteúdo de ácido ascórbico foi estimado com base na diferença entre o branco e o resultado da diferença dessas leituras (Keller \& Schwager, 1977).

A atividade da enzima superóxido dismutase (SOD) foi determinada de acordo com Osswald et al. (1992). Folhas frescas $(0,35 \mathrm{~g})$ foram homogeneizadas com PVPP e solução contendo tampão fosfato $(50 \mathrm{mM}$, pH 7,5), EDTA- $\mathrm{Na}_{2} 1 \mathrm{mM}, \mathrm{NaCl} 50 \mathrm{mM}$ e ácido ascórbico $1 \mathrm{mM}$ e centrifugadas $(22.000 \mathrm{~g}, 25 \mathrm{~min}$, a $2^{\circ} \mathrm{C}$ ). Ao sobrenadante foram adicionados $0,5 \mathrm{~mL}$ de EDTA-Na $\mathrm{Na}_{2} 0,54 \mathrm{mM}, 0,8 \mathrm{~mL}$ de tampão fosfato de potássio $(0,1 \mathrm{M}, \mathrm{pH} 7), 0,5 \mathrm{~mL}$ de metionina $0,13 \mathrm{mM}$, $0,5 \mathrm{~mL}$ de azul $p$-nitrotetrazólio (NBT) $0,44 \mathrm{mM}$ e $0,2 \mathrm{~mL}$ de riboflavina $1 \mathrm{mM}$, e a solução resultante foi exposta à luz fluorescente $(80 \mathrm{~W})$ por $30 \mathrm{~min}$. Extratos preparados seguindo o mesmo procedimento foram mantidos no escuro. A absorbância da solução foi medida em espectrofotômetro ( $\lambda=560 \mathrm{~nm}$ ) em ambos os tipos de extrato (iluminado e não iluminado) e a diferença entre as duas absorbâncias foi considerada para a determinação da atividade da SOD, que consistiu na inibição da redução do NBT, pela dismutação enzimática do superóxido.

Durante o trabalho, as condições de temperatura, umidade relativa e radiação fotossinteticamente ativa foram monitoradas. Os valores médios de temperatura e umidade relativa foram $27^{\circ} \mathrm{C} \mathrm{e} 77 \%$, respectivamente, com máximo e mínimo de temperatura de 37 e $20^{\circ} \mathrm{C}$ e de umidade relativa de 94 e 39\%. A irradiância média, do período de 12 horas diárias, foi de $700 \mu \mathrm{mol} \mathrm{m}^{-2} \mathrm{~s}^{-1}$, com valores máximos de $1.800 \mu \mathrm{mol} \mathrm{m}^{-2} \mathrm{~s}^{-1}$ nos dias ensolarados e $100 \mu \mathrm{mol} \mathrm{m}^{-2} \mathrm{~s}^{-1}$ nos dias nublados.

As diferenças entre os tratamentos foram avaliadas pelo teste t, utilizando-se o programa Sigma Stat (Jandel Scientific, 1994). Também foi realizada análise de componentes principais (ACP) para avaliar as respostas das variáveis em relação aos tratamentos, utilizando-se programa PCOrd (McCune \& Mefford, 1999). A ACP separa as variáveis, estatisticamente mais relevantes dentro do desenho experimental, que explicam a variabilidade das medidas.

\section{Resultados e Discussão}

As trocas gasosas nas plântulas de soja foram mais elevadas aos 20 dias após a semeadura do que aos 10 dias, em ambos os tratamentos, $\mathrm{AF}$ e $\mathrm{AF}+\mathrm{O}_{3}$ (Tabela 1). Isto possivelmente ocorreu porque, aos 20 dias, as plântulas haviam deixado de depender das

Tabela 1. Fotossíntese líquida ( $\left.\mu \mathrm{mol} \mathrm{m} \mathrm{m}^{-2} \mathrm{~s}^{-1}\right)$, condutância estomática $\left(\mathrm{mol} \mathrm{m} \mathrm{m}^{-2} \mathrm{~s}^{-1}\right)$, transpiração $\left(\mathrm{mmol} \mathrm{m}^{-2} \mathrm{~s}^{-1}\right)$, altura $\left(\mathrm{cm}^{2}\right.$ ), comprimento da raiz $(\mathrm{cm})$, diâmetro do caule $(\mathrm{cm})$, área foliar $\left(\mathrm{cm}^{2}\right)$, biomassa total $(\mathrm{g})$ e razão raiz:parte aérea de plântulas de soja 'Tracajá' aos 10 e 20 dias após a semeadura e ácido ascórbico $\left(\mathrm{mg} \mathrm{g}^{-1}\right)$ e atividade da enzima superóxido dismutase (unidade de SOD) em plântulas de soja 'Tracajá' aos 20 dias após a semeadura, sob condições controladas de fumigação.

\begin{tabular}{|c|c|c|c|c|}
\hline \multirow{2}{*}{ Variáveis } & \multicolumn{2}{|c|}{10 dias após a semeadura } & \multicolumn{2}{|c|}{20 dias após a semeadura } \\
\hline & $\mathrm{AF}$ & $\mathrm{AF}+\mathrm{O}_{3}$ & $\mathrm{AF}$ & $\mathrm{AF}+\mathrm{O}_{3}$ \\
\hline Fotossíntese líquida & $11,84^{*}$ & 9,95 & $17,00^{*}$ & 13,60 \\
\hline Condutância estomática & $0,59^{*}$ & 0,43 & $0,75^{*}$ & 0,59 \\
\hline Transpiração & $9,00 *$ & 7,91 & $9,61 *$ & 7,69 \\
\hline Altura & $17,5^{*}$ & 13,6 & $35,9 *$ & 33,6 \\
\hline Comprimento da raiz & 7,33 & 7,55 & $10,20 *$ & 9,16 \\
\hline Diâmetro do caule & 0,12 & $0,14^{*}$ & $0,20 *$ & 0,17 \\
\hline Área foliar & $12,10 *$ & 8,55 & $80,70 *$ & 58,60 \\
\hline Biomassa total & $0,11^{*}$ & 0,09 & $0,48 *$ & 0,38 \\
\hline Razão raiz:parte aérea & 0,230 & 0,210 & $0,064 *$ & 0,056 \\
\hline Ácido ascórbico & - & - & 18,6 & $22,8^{*}$ \\
\hline Superóxido dismutase & - & - & 101 & $140 *$ \\
\hline
\end{tabular}

* Significativo a $5 \%$ de probabilidade, pelo teste $\mathrm{t}$. 
reservas dos cotilédones; estes já haviam caído ou, quando ainda presentes, as plântulas dependiam menos deles e mais do processo fotossintético.

A exposição ao ozônio reduziu as trocas gasosas nas plantas do tratamento $\mathrm{AF}+\mathrm{O}_{3}$ tanto aos 10 como aos 20 dias após a semeadura, quando comparado ao tratamento AF (Tabela 1). Aos 10 dias, esta redução foi de 16,27 e $12 \%$, respectivamente, para fotossíntese líquida, condutância estomática e transpiração. Aos 20 dias, as reduções da fotossíntese líquida (20\%) e da transpiração (20\%) foram mais pronunciadas, ao passo que a condutância estomática apresentou uma redução mais baixa (21\%), quando comparada com as plântulas aos 10 dias após a semeadura. A diminuição na fotossíntese líquida nas plântulas expostas ao ozônio pode ter sido causada por distúrbios em várias etapas do processo fotossintético, provocados pelo estresse oxidativo devido à produção de espécies ativas de oxigênio. Estudos mostram que a carboxilação é, geralmente, a etapa mais vulnerável, pois a ribulose bifosfato carboxilase-oxigenase (Rubisco) tem sua síntese e atividade reduzida (Pell et al., 1994; Farage \& Long, 1999; Zheng et al., 2002).

A redução da condutância estomática pode ser causa ou efeito da menor assimilação de carbono (Bortier et al., 2000; Zheng et al., 2002). No entanto, o fato de, aos 10 dias, a porcentagem de redução entre o tratamento $\mathrm{AF}$ e $\mathrm{AF}+\mathrm{O}_{3}(27 \%)$ ter sido maior do que aos 20 dias $(21 \%)$ pode indicar que as plântulas expostas ao ozônio diminuíram sua capacidade de regular a condutância com o prolongamento da exposição. Com condutância estomática mais alta, há maior fluxo de ozônio para o interior da folha e, assim, maior estresse oxidativo, o que pode ter sido a causa da maior redução da fotossíntese e da transpiração aos 20 dias, em comparação com as plântulas do tratamento AF.

A redução das trocas gasosas influenciou o crescimento e acúmulo de biomassa, que também foram reduzidos nas plântulas do tratamento $\mathrm{AF}+\mathrm{O}_{3}$ (Tabela 1). Dez dias após a semeadura, estas plântulas apresentaram valores médios de crescimento em altura, área foliar e biomassa menores do que as plântulas do tratamento AF. Aos 20 dias, além destes parâmetros, comprimento da raiz, diâmetro do caule e razão entre biomassa radicular e epígea também foram reduzidos.

As alterações no crescimento e produção de biomassa nas plântulas do tratamento $\mathrm{AF}+\mathrm{O}_{3}$ também podem ser decorrentes de desequilíbrios nutricionais causados pela redução da biomassa radicular e possível mudança na absorção de nutrientes pela planta (Oksanen, 2001). A redução da disponibilidade de nutrientes pode atingir vias metabólicas, inibir enzimas destas vias, afetar o metabolismo de carboidratos, bem como as vias de transporte de nutrientes entre as partes da planta (Oksanen \& Saleem, 1999; Postiglione et al., 2000; Morgan et al., 2003).

A concentração de ácido ascórbico e a atividade da enzima superóxido dismutase, em plântulas de soja 'Tracajá' aos 20 dias após a semeadura, foram maiores 18 e $28 \%$, respectivamente, no tratamento $\mathrm{AF}+\mathrm{O}_{3}$ (Tabela 1). As plântulas devem ter desviado energia do crescimento para investir em defesas antioxidativas. Contudo, o aumento em defesas nem sempre é capaz de evitar danos às plantas (Filella et al., 2005). Booker \& Fiscus (2005) também observaram aumento das defesas antioxidativas em plantas de soja expostas ao ozônio, no entanto, assim como no presente trabalho, a fotossíntese líquida e o crescimento também diminuíram.

A análise de componentes principais (ACP) resumiu $78,5 \%$ da variabilidade total dos dados nos dois primeiros eixos: o primeiro eixo representou $58,3 \%$ da variabilidade das medidas e o segundo 20,2\% (Figura 1). No lado positivo do eixo 1 , foram alocadas unidades amostrais referentes às plântulas do tratamento $\mathrm{AF}$, as quais foram

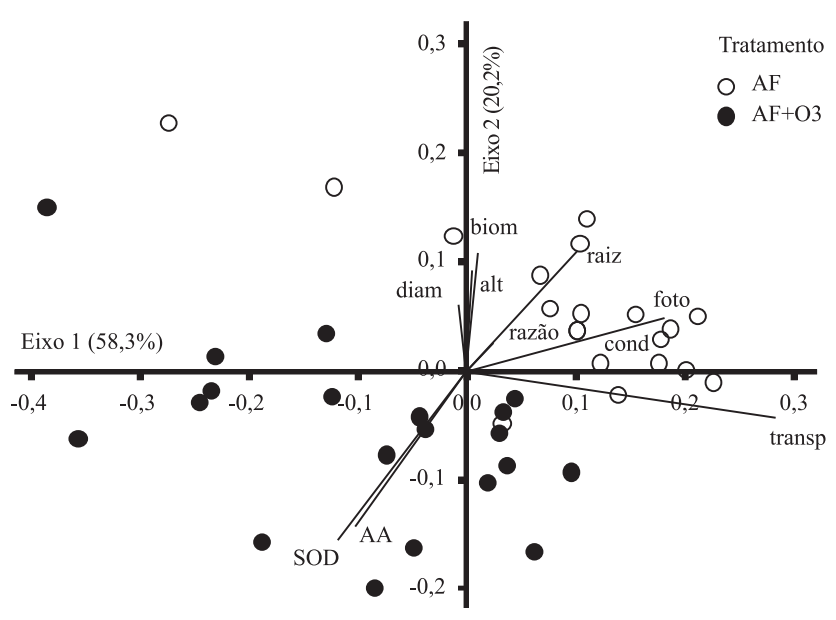

Figura 1. Análise de componentes principais (ACP) das variáveis biológicas avaliadas nas plântulas de soja 'Tracajá' 20 dias após a semeadura, sob condições controladas de fumigação. alt: altura; raiz: comprimento da raiz; diam: diâmetro do caule; biom: biomassa; razão: raiz:parte aérea; foto: fotossíntese líquida; cond: condutância estomática; transp: transpiração; AA: ácido ascórbico; SOD: superóxido dismutase. 
fortemente associadas a altos valores de transpiração, fotossíntese líquida e condutância estomática. Estas variáveis foram altamente correlacionadas com o eixo 1 (Tabela 2). Diferentemente, no lado negativo do eixo 1, encontraram-se as unidades amostrais das plântulas do tratamento $\mathrm{AF}+\mathrm{O}_{3}$ associadas a altos valores de ácido ascórbico e superóxido dismutase. As defesas antioxidativas apresentaram as maiores correlações com o eixo 2. Desta forma, a ACP traduziu, principalmente pelo eixo 1 , a resposta das plântulas de soja à diferença entre os tratamentos.

A redução das trocas gasosas, do crescimento e acúmulo de biomassa da cultivar estudada foi alta, considerando a concentração a qual as plântulas foram submetidas. Além disso, estas mesmas plântulas expostas ao ozônio apresentaram mudanças no padrão de emissão de compostos orgânicos voláteis e danos foliares visíveis, parâmetros que ainda necessitam de maior investigação, mas que também indicam a sensibilidade desta cultivar ao ozônio.

Esses resultados indicam uma possível perda de produtividade da soja causada pela exposição ao ozônio. Heagle et al. (1999) e Britz \& Robinson (2001) observaram que diferentes cultivares de soja utilizadas na agricultura norte-americana quando expostas ao ozônio, diminuíram a produção de biomassa e grãos podendo ocorrer prejuízos econômicos de até US\$ 4,00 bilhões ao ano (Ashmore, 2005). Ao avaliar a sensibilidade ao ozônio das espécies de maior importância econômica cultivadas na China, Europa e Estados Unidos, Chameides et al. (1999) e Aunan et al. (2000), Mills et al. (2000) e Ashmore (2003), respectivamente, concluíram que a soja é uma das espécies mais sensíveis.

Os resultados deste trabalho indicam os danos potenciais do ozônio ao cultivo da soja em regiões

Tabela 2. Correlação de Pearson e Kendall das variáveis biológicas com os eixos 1 e 2.

\begin{tabular}{lcc}
\hline Variáveis & Eixo 1 & Eixo 2 \\
\hline Altura & 0,130 & 0,532 \\
Comprimento da raiz & 0,555 & 0,574 \\
Diâmetro do caule & $-0,162$ & 0,425 \\
Biomassa & 0,193 & 0,572 \\
Raiz/parte aérea & 0,269 & 0,275 \\
Fotossíntese líquida & 0,739 & 0,385 \\
Condutância estomática & 0,617 & $-0,055$ \\
Transpiração & 0,924 & $-0,365$ \\
Ácido ascórbico & $-0,556$ & $-0,655$ \\
Superóxido dismutase & $-0,593$ & $-0,685$ \\
\hline
\end{tabular}

brasileiras, especialmente as que recebem as plumas das queimadas da Amazônia, uma vez que Cordova Leal et al. (2003) e Artaxo et al. (2005) registraram, durante o período das queimadas, concentração atmosférica de ozônio três vezes mais alta do que a utilizada neste trabalho.

\section{Conclusões}

1. Aos 10 dias após a semeadura, plântulas de soja 'Tracajá' expostas ao ozônio apresentam valores médios de fotossíntese líquida, condutância estomática, transpiração, altura, área foliar e biomassa menores.

2. Aos 20 dias após a semeadura, além desses parâmetros, plântulas de soja 'Tracajá' expostas ao ozônio apresentam valores médios de comprimento da raiz, diâmetro do caule e razão raiz:parte aérea menores e concentração de ácido ascórbico e atividade da enzima superóxido dismutase elevadas.

\section{Agradecimentos}

Ao CNPq, pela bolsa concedida e pelo apoio financeiro; à Fundação de Amparo à Pesquisa do Estado de São Paulo, pelo financiamento da construção do sistema de fumigação; à Embrapa Soja, pelo fornecimento das sementes; ao Prof. Dr. Welington Braz Carvalho Delitti da Universidade de São Paulo, Instituto de Biociências, Dep. de Ecologia, pelo empréstimo do analisador de gases por infravermelho.

\section{Referências}

ARTAXO, P.; DIAS, M.A.F.S.; ANDREAE, M.O. O mecanismo da floresta para fazer chover. Scientific American Brasil, v.1, p.3845, 2003.

ARTAXO, P.; FERNANDES, E.T.; MARTINS, J.V.; YAMASOE, M.A.; HOBBS, P.V.; MAENHAUT, W.; LONGO, K.M.; CASTANHO, A. Large-scale aerosol source apportionment in Amazonia. Journal of Geophysical Research, v.103, p.3183731848, 1998.

ARTAXO, P.; GATTI, L.V.; LEAL, A.M.C.; LONGO, K.M.; FREITAS, S.R.; LARA, L.I.; PAULIQUEVIS, T.M.; PROCÓPIO, A.S.; RIZZO, L.V. Química atmosférica na Amazônia: a floresta e as emissões de queimadas controlando a composição da atmosfera amazônica. Acta Amazonica, v.35, p.185-196, 2005.

ASHMORE, M.R. Assessing the future global impacts of ozone on vegetation. Plant, Cell and Environment, v.28, p.949-964, 2005.

ASHMORE, M.R. Effects of oxidants at the whole plant and community level. In: BELL, J.N.B.; TRESHOW, M. (Ed.). Air pollution and plant life. $2^{\text {nd }}$ ed. New York: J. Wiley, 2003. p.89-118. 
AUNAN, K.; BERNTSEN, T.K.; SEIP, H.M. Surface ozone in China and its possible impact on agricultural crop yields. Ambio, v.29, p.294-301, 2000.

BOOKER, F.L.; FISCUS, E. The role of ozone flux and antioxidants in the suppression of ozone injury by elevated $\mathrm{CO}_{2}$ in soybean. Journal of Experimental Botany, v.56, p.2139-2151, 2005.

BORTIER, K.; CEULEMANS, R.; DE TEMMERMAN, L. Effects of ozone exposure in open-top chambers on poplar (Populus nigra) and beech (Fagus sylvatica): a comparison. Environmental Pollution, v.109, p.509-516, 2000.

BRITZ, S.J.; ROBINSON, M.J. Chronic ozone exposure and photosynthate partitioning into starch in soybean leaves. International Journal of Plant Sciences, v.162, p.111-117, 2001.

CHAMEIDES, W.L.; XINGSHENG, L.; XIAOYAN, T.; XIUJI, Z.; CHAO, L.; KIANG, C.S.; JOHN, J.S.; SAYLOR, R.D.; LIU, S.C.; LAM, K.S. Is ozone pollution affecting crop yield in China? Geophysical Research Letters, v.26, p.867-870, 1999.

CORDOVA LEAL, A.M. Gases traço na Amazônia: variabilidade sazonal e temporal de $\mathrm{O}_{3}$, NOx e $\mathrm{CO}$ em ambientes de pastagem e floresta. 2003. Tese (Doutorado) - Universidade de São Paulo, São Paulo.

EMBERSON, L. Air pollution on crops and forests: an introduction. In: EMBERSON, L.; ASHMORE, M.; MURRAY, F. (Ed.). Air pollutions on crops and forests, a global assessment. Singapore: Imperial College Press, 2003. p.3-34.

FARAGE, P.K.; LONG, S.P. The effects of $\mathrm{O}_{3}$ fumigation during leaf development on photosynthesis of wheat and pea: an in vivo analysis. Photosynthesis Research, v.59, p.1-7, 1999.

FILELLA, I.; PEÑUELAS, J.; RIBAS, A. Using plant biomonitors and flux modeling to develop $\mathrm{O}_{3}$ dose-response relationships in Catalonia. Environmental Pollution, v.134, p.145-154, 2005.

FREITAS, S.R.; LONGO, K.M.; DIAS, M.A.F.S.; DIAS, P.L.S.; CHATFIELD, R.; PRINS, E.; ARTAXO, P.; RECUERO, F.S. Monitoring the transport of biomass burning emissions in South America. Environmental Fluid Mechanics, v.5, p.135-167, 2004.

FUHRER, J.; BOOKER, F. Ecological issues related to ozone: agricultural issues. Environmental International, v.29, p.141-154, 2003.

FUHRER, J.; SKÄRBY, L.; ASHMORE, M.R. Critical levels for ozone effects on vegetation in Europe. Environmental Pollution, v.97, p.91-106, 1997.

GUYON, P.; FRANK, G.; WELLING, M.; CHAND, D.; ARTAXO, P.; NISHIOKA, G.; RIZZO, L.V.; LLOYD, J.; KOLLE, O.; DIAS, M.A.F.S.; GATTI, L.V.; CORDOVA, A.M.; ANDREAE, M.O. Airborne measurements of trace gases and aerosol particles emissions from biomass burning in Amazonia. Atmospheric Chemistry and Physics, v.5, p.2989-3002, 2005. HEAGLE, A.S.; MILLER, J.E.; PURSLEY, W.A. Influence of ozone stress on soybean response to carbon dioxide enrichment. III. Yield and seed quality. Crop Science, v.38, p.128-134, 1999.

JANDEL SCIENTIFIC. SigmaStat statistical software: user's manual. San Rafael, 1994. 831p.

KELLER, T.; SCHWAGER, H. Air pollution and ascorbate. European Journal of Forest Pathology, v.7, p.338-350, 1977.

McCUNE, B.; MEFFORD, M.J. PC-ORD for Windows: multivariate analysis of ecological data. Version 4.10. Oregon: MjM Sofware Desing, 1999. 47p.

MELLO FILHO, O.L.; SEDIYAMA, C.S.; MOREIRA, M.A.; REIS, M.S.; MASSONI, G.A.; PIOVESAN, N.D. Grain yield and seed quality of soybean select for high protein content. Pesquisa Agropecuária Brasileira, v.39, p.445-451, 2004.

MILLS, G.; HAYES, F.; BUSE, A.; REYNOLDS, B. Air pollution and vegetation: UNECE ICP vegetation, annual report 1999/2000. Bangor: Centre for Ecology and Hydrology, 2000. 52p.

MORGAN, P.B.; AINSWORTH, E.A.; LONG, S.P. How does elevated ozone impact soybean? A meta-analysis of photosynthesis, growth and yield. Plant, Cell and Environment, v.26, p.1317$1328,2003$.

OKSANEN, E.; SALEEM, A. Ozone exposure results in various carryover effects and prolonged reduction in biomass in birch (Betula pendula Roth). Plant, Cell and Environment, v.22, p.1401-1411, 1999.

OKSANEN, E.J. Increasing tropospheric ozone level reduced birch (Betula pendula) dry mass within a five years period. Water, Air and Soil Pollution, v.130, p.947-952, 2001.

OSSWALD, W.F.; KRAUS, R.; HIPPELI, S.; BENZ, B.; VOLPERT, R.; ELSTNER, E.F. Comparison of the enzymatic actives of dehydroascorbic acid redutase, glutathione redutase, catalase, peroxidase and superoxide dismutase of healthy and damaged spruce needles (Picea abies (L.) Karst). Journal of Plant Physiology, v.139, p.742-748, 1992.

PELL, E.J.; ECKART, N.A.; GLICK, R.E. Biochemical and molecular basis for impairment of photosynthesis potential. Photosynthesis Research, v.39, p.453-462, 1994.

POSTIGLIONE, L.; FAGNANO, M.; MEROLA, G. Response to ambient ozone of two white clover (Trifolium repens L. cv. Regal) clones, one resistant and one sensitive, grown in a Mediterranean environment. Environmental Pollution, v.109, p.525-531, 2000.

ZHENG, Y.; SHIMIZY, H.; BARNES, J.D. Limitations to $\mathrm{CO}_{2}$ assimilation in ozone-exposed leaves of Plantago major. New Phytologist, v.155, p.67-78, 2002.

Recebido em 13 de julho de 2006 e aprovado em 19 de abril de 2007 